\title{
El lugar del otro en la evangelización. Lectura teológica de la pluralidad religiosa en Chile. ${ }^{1}$ \\ Catalina Cerda-Planas \\ INSTITUTO DE PASTORAL APÓSTOL SANTIAGO, ARZOBISPADO DE SANTIAGO \\ cacerdap@uc.cl
}

\section{INTRODUCCIÓN}

En la conferencia que a continuación presentaré quisiera problematizar la comprensión de la evangelización como transmisión de la fe -tan presente en la reflexión teológico-pastoral actual y en algunos de sus antecedentes magisteriales más relevantes- proponiendo más bien, a la luz de la teología contemporánea, que esta sea entendida como comunicación de la fe. Ello supone reconocer el lugar y valor del sujeto interlocutor en dicho proceso, incluso en sociedades cada vez más plurales como la chilena. Un giro de este tipo implica importantes desafíos tanto para la acción evangelizadora de la Iglesia como para la teología pastoral.

\section{LA EVANGELIZACIÓN CRISTIANA EN UNA SOCIEDAD PLURAL}

La celebración de la V Conferencia General del Episcopado Latinoamericano y del Caribe en Aparecida, Brasil, el año 2007 ha significado para la Iglesia local un fuerte reimpulso a su misión evangelizadora en el contexto de un continente cada vez más plural, también en términos religiosos. Ello supone, desde la perspectiva de Aparecida, salir al encuentro del mundo, especialmente de los más alejados, para conocer mejor la situación del Continente y reconocer allí las preguntas y anhelos del hombre de hoy. Todo ello, en vistas a poder anunciar de manera más significativa a Jesucristo como respuesta de Vida Plena ${ }^{2}$.

1 La presente conferencia fue presentada como ponencia en el II Congreso Internacional del Centro de Estudios de la Religión UC que se llevó a efecto entre el 5 y el 7 de septiembre de 2018 y versó sobre "Diversidad de creencias y sentido en una sociedad plural".

2 Cfr. Capítulo conclusivo en Conferencia Episcopal Latinoamericana y del Caribe (CELAM), Documento conclusivo V Conferencia General del Episcopado Latinoamericano y del Caribe en Aparecida (Santiago, Chile: Conferencia Episcopal de Chile, 2007). 
El Papa Francisco, por su parte, ha significado una nueva energía a este impulso misionero, enfatizando, además de lo anterior, que dicho anuncio es para todos, sin diferenciar por condición, si se han alejado o han sido excluidos, si dicen no creer en nada o buscan explícitamente la $\mathrm{fe}^{3}$. Por ello, el Papa Francisco ha sido enfático en que espera una Iglesia volcada hacia fuera, en salida, en las calles, en los lugares públicos o en aquellos espacios privados en que se gesta la vida personal y social. Una Iglesia que pierde el miedo al movimiento, al conflicto, o incluso a salir herida en el proceso $^{4}$.

Ahora bien, la renovación misionera de la Iglesia supone que los miembros de las comunidades y cristianos en general entren en contacto más intencionado con la cultura y con la sociedad actual. En el caso de Chile, la sociedad a la cual los misioneros cristianos son enviados ha vivido importantes transformaciones sociales, culturales y religiosas en los últimos años, en la dirección de la pluralización de cosmovisiones y de creencias, que es el tema central del presente Congreso. Dado que no es el foco principal de esta conferencia, no será posible profundizar en estas transformaciones socioculturales. Con todo, valga mencionar que los procesos de cambio religioso en Chile en las últimas décadas se centran, de manera principal, en la disminución de la afiliación católica (actualmente en torno al 59\%), atenazada por otros dos fenómenos: el aumento, sutil y sostenido aunque ahora relativamente estancado, del pentecostalismo que hoy representa al 17\% de los chilenos, así como el abrupto aumento de la desafiliación religiosa e increencia que en la actualidad alcanza un 19\% ${ }^{5}$. Sin embargo, destaca la permanencia de la creencia en Dios, ya que solo un $6 \%$ de los chilenos afirma no creer en É $l^{6}$.

3 CELAM, Documento conclusivo V Conferencia..., 23.

4 Cfr. Papa Francisco, «Discurso en la Jornada Mundial de la Juventud, Río de Janeiro», 2013, acceso el 18 de agosto de 2016, https://www.aciprensa.com/noticias/texto-completo-discurso-del-papa-francisco-en-encuentro-con-jovenes-argentinos-88631/.

5 Cfr. Universidad Católica - Adimark, Encuesta Nacional Bicentenario (Santiago, Chile, 2017), acceso el 29 de octubre de 2017, http://encuestabicentenario.uc.cl/.

6 Cfr. Universidad Católica - Adimark, Encuesta Nacional Bicentenario, 2017. 
Es por esta razón que autores como Parker han hecho notar que en el país se vive un proceso de notorio debilitamiento del catolicismo en su expresión institucionalizada, pero no necesariamente un declive de la religión, incluso entre aquellos que se definen a sí mismos como sin religión ${ }^{7}$. Esto implicaría que la religiosidad se está transformando y que quizás está surgiendo, en línea con los procesos de cambio cultural, un nuevo sujeto religioso que elige libremente entre aquellos aspectos religiosos con los que se siente relacionado. Todo lo anterior como procesos que afectan a toda la sociedad pero que se visibilizan con más fuerza en las generaciones más jóvenes ${ }^{8}$.

Ante esta conjunción de elementos -renovación del impulso misionero de la Iglesia y pluralización religiosa de la sociedad chilena- surge la inevitable pregunta acerca de cómo comprender y desarrollar la acción evangelizadora a la cual Aparecida y el Papa Francisco han impulsado con fuerza: ¿Como recuperación de quienes se han perdido de la fe católica? ¿O como anuncio de un mensaje o transmisión de un sistema de creencias que quien anuncia tiene y que no está en quienes lo reciben (dada la pluralidad religiosa)? ¿O como identificación y potenciación de la experiencia religiosa que puede estar presente en los interlocutores? ¿Cuál es, en definitiva, el lugar y valor que se les reconoce a los otros en el proceso de evangelización?

La hipótesis que intentaré mostrar en lo que sigue es que actualmente la acción misionera de la Iglesia se entiende principalmente como transmisión de la fe, es decir, como un acto fundamentalmente unidireccional en el que el misionero entrega un mensaje que pareciera no estar presente en el receptor del anuncio. Ello supone, entre otras cosas, minusvalorar el lugar y el valor que el otro tiene en el proceso de evangelización. Pero además, dicha comprensión y forma de desarrollar la evangelización no se condice con una correcta comprensión de la revelación de Dios en la historia, por lo cual debiese ser enriquecida, pasando a ser entendida ya no como transmisión sino como comunicación de la fe. Ello significaría reconocer

7 Cfr. Cristián PARKer, «Education and Increasing Religious Pluralism in Latin America: The case of Chile», en Religious Pluralism, Democracy, and the Catholic Church in Latin America (Notre Dame, IN: University of Notre Dame Press, 2009), 137.

8 Al mismo diagnóstico ha llegado también Bahamondes. Cfr. Luis Bahamondes (ed.), Transformaciones y alternativas religiosas en América Latina (Santiago, Chile: Centro de Estudios Judaicos, 2013). 
el lugar propio del otro que pasa a ser comprendido como interlocutor en el proceso de evangelización, incluso en contextos de mayor pluralización. Todo lo anterior, supone importantes desafíos para la acción misionera así como también para la teología pastoral.

\section{De LA TRANSMISIÓN A LA COMUNICACIÓN DE LA FE: LA EVANGELIZACIÓN como des-Velamiento de la universal autocomunicación de Dios EN LA HISTORIA}

El documento de la V Conferencia no aborda de manera sistemática una conceptualización de la evangelización ni del lugar de los interlocutores en dicho proceso. Sin embargo, una lectura transversal del documento, analizando sus supuestos teológico-pastorales, hace posible visualizar que prima en él una comprensión de la evangelización fundamentalmente como transmisión de la fe, es decir, como una vocación del discípulo por anunciar y compartir su propia experiencia de encuentro con Jesucristo que ha sido una Buena Noticia para él o para ella. Una experiencia que se supone que el receptor de la misión no ha vivido o solo la ha vivido débilmente. Ello porque en prácticamente en ninguna parte del documento se menciona al otro con quien se encuentra el discípulo misionero como alguien que pudiera ya estar viviendo dicha experiencia, aunque sea de manera atemática. Tal vez con la sola excepción de la valoración de la religiosidad popular como expresión de un anhelo de Dios ${ }^{9}$, el documento no explicita el valor o aporte del otro en este encuentro que la Iglesia está llamada a realizar con él en el proceso misionero. Ello implica reconocerle a la realidad el lugar de receptor que más bien debe ser conocido para identificar sus preguntas y anhelos y así poder transmitir de manera más efectiva el mensaje cristiano.

En algún sentido, ello se corresponde con sus antecedentes teológicopastorales como pueden ser las anteriores conferencias generales del episcopado latinoamericano e incluso el Concilio Vaticano II. Este último, hace ya más de 50 años, significó una importante novedad para su tiempo, en cuanto que en él se reconocía que la relación de la Iglesia con el mundo debía estar fundada en el diálogo. Pero nuevamente porque dicho diálogo le ayuda a la Iglesia a identificar los problemas más urgentes de hoy y le entrega las categorías más significativas o los mejores medios para decir,

9 Cfr. CELAM, Documento conclusivo V Conferencia..., 93. 
de una manera nueva y actualizada, las verdades de la fe en el mundo contemporáneo ${ }^{10}$.

Sin embargo, el Concilio Vaticano II significó, en otro de sus textos principales, una renovación en la forma en que la Iglesia comprendió la revelación y el lugar del mundo y de la historia en ella. De hecho, el giro teológico del siglo XX ha permitido redescubrir el carácter eminentemente histórico de la revelación y a la historia -toda historia- como el único lugar en el que Dios se revela y se sigue revelando ${ }^{11}$. Es por ello que en la Constitución Dogmática Dei Verbum la revelación es tematizada fundamentalmente como una Historia de Salvación, la cual comienza con el mismísimo acto de creación por parte de Dios ${ }^{12}$. Por tanto, para el cristianismo, la historia no es un "mero escenario" (externo) de la acción agraciante de Dios para con su humanidad, sino que se transforma en verdadero lugar teológico dado que ella misma es despliegue de la auto-comunicación de Dios en su humanidad ${ }^{13}$. Y que dicha Historia de Salvación acontece en toda historia humana, no sólo en sus aspectos propiamente religiosos ${ }^{14}$.

10 Véase, a este respecto, dos textos ilustrativos respecto de la valoración de la cultura por parte de la Iglesia en el documento de la Gaudium et Spes, el cual ha servido como inspiración para la renovación pastoral de la Iglesia post-conciliar: el número 58, titulado "Múltiples conexiones entre la buena nueva de Cristo y la cultura" y el número 44, el cual tematiza directamente la ayuda que recibe la Iglesia del mundo moderno. Cfr. Concilio Vaticano II, «Constitución Pastoral sobre la Iglesia en el mundo actual Gaudium et Spes», en Documentos del Vaticano II: constituciones, decretos, declaraciones (Madrid: Biblioteca de Autores Cristianos, 1965), 44, 58.

11 Cfr. Karl Rahner, Curso Fundamental de la Fe (Barcelona: Herder, 2007), 172 y 174.

12 Cfr. Concilio Vaticano II, Constitución Dogmática..., 3-4.

13 Melchor Cano, en su ya clásica categorización de los lugares teológicos, incorpora a la historia como uno de ellos. Con todo, dicho autor la menciona como un loci alieni, es decir, no propio, secundario respecto de la Sagrada Escritura, la Tradición, la autoridad de la Iglesia, entre otros. Me parece que la perspectiva teológica del siglo XX, recogida y fortalecida por el Concilio Vaticano II, da mayor fuerza y centralidad a la historia como lugar teológico, al acoger el giro del pensamiento filosófico moderno en el cual se reconoce la historicidad como dimensión constitutiva de la realidad (incluso del ser, en lenguaje metafísico clásico) y, por tanto, en materia teológica, de la revelación de Dios al hombre. Cfr. para este último punto, Hünermann, El Vaticano II como software..., 41-70.

14 Cfr. Rahner, Curso Fundamental..., 179. 
De lo hasta aquí dicho se desprende, desde una perspectiva antropológica, una doble afirmación: primero, que el hombre lleva en sí la posibilidad de percibir y recibir la auto-comunicación de Dios en la historia; y, segundo, la libertad del ser humano de aceptar o rechazar lo propuesto por Dios. Dios se ofrece a todos y todo ser humano está capacitado para escucharlo y percibir su oferta ${ }^{15}$, aunque ello no signifique, inmediatamente, la libre aceptación de Dios por parte de todo hombre ${ }^{16}$ :

Nuestro enunciado fundamental no es una afirmación que valga tan sólo para este o el otro hombre a diferencia de los demás, o sea, p. ej., sólo para los bautizados, para los justificados, a diferencia de los paganos y pecadores. La tesis de que el hombre como sujeto es el evento de la autocomunicación de Dios [...] es una frase que se refiere en absoluto a todos los hombres, que expresa un existencial de cada hombre ${ }^{17}$.

La afirmación de que todo hombre es el evento de la autocomunicación de Dios, incluso antes de la aceptación o rechazo de Dios por parte del individuo libre, implica reconocer a toda persona como lugar de revelación, es decir, como un interlocutor en quien encuentro a Dios auto-comunicándose. Así, la experiencia de Dios acontece (aunque sea atemáticamente) siempre y en tanto se realiza la subjetividad y trascendentalidad del ser humano. En este sentido, todo el mundo es posible mediación con Dios y, por tanto, para el cristianismo no hay ningún ámbito sacral delimitable como el único para encontrar a Dios.

Por ello, el otro hacia el cual la Iglesia sale al encuentro, no es una tabula rasa ni un mero receptáculo de la novedad del Evangelio. Tomar en serio el carácter universal de la acción redentora de Dios que se revela en la historia requiere reconocer que en todos los hombres de buena voluntad -no solo en aquellos que ya son explícitamente cristianosobra la gracia de modo invisible ${ }^{18}$. En ellos, de alguna manera, el Dios de Jesucristo se está autocomunicando y, por tanto, su experiencia, su vida,

\footnotetext{
15 Cfr. Karl Rahner, Oyente de la Palabra (Barcelona: Herder, 1967), 90.

16 Karl Rahner, Curso Fundamental ..., 160.

17 Karl Rahner, Curso Fundamental ..., 160.

18 Cfr. Concilio Vaticano II, Constitución Pastoral..., 22.
} 
su historia, son lugar y contenido de la revelación, en los cuales Dios puede ser encontrado y reconocido.

Reconocer aquello supone, a su vez, una modificación cualitativa de la acción evangelizadora de la Iglesia ${ }^{19}$ : el encuentro con el otro que no es parte de la comunidad eclesial, no es el encuentro con un ser vacío de Dios a quien yo debo ir a entregarle algo que pareciera no experimentar o no ser capaz de recibir. La misión debe ser comprendida y desarrollada como una acción profundamente dia-lógica, orientada más bien a de-velar, a des-cubrir, a evidenciar la presencia ya actuante de Dios en todas las personas: en aquellos que, aun reconociéndose religiosos, se han alejado, en los no cristianos e incluso en personas no creyentes.

Por tanto, dicha evangelización a la cual hoy la Iglesia vuelve a llamar debe ser entendida fundamentalmente como un acto de comunicación de la fe -y ya no de transmisión-, en un doble sentido: como acción de anuncio/testimonio de la propia experiencia (personal y comunitaria) de encuentro con Dios que se comparte "por desborde de gratitud y alegría"20. Comunicación que si quiere ser tal, debe lograr ser entendida y asimilada por el interlocutor, de modo que el mensaje no sea solo escuchado sino también recepcionado significativamente ${ }^{21}$. En este primer sentido, la evangelización supone, tal como ya lo han dicho el Vaticano II y Aparecida, conocer a los interlocutores -su manera de hablar, sus símbolos, su tradición- para poder entregar el mensaje de manera que sea recibido y aceptado como relevante ${ }^{22}$.

Pero es necesario ir más allá. A la luz de lo anterior, es necesario afirmar que el mundo no es un mero receptor del anuncio cristiano, sino un verdadero interlocutor en esta comunicación de la fe que es la

19 Me refiero aquí a la evangelización en tanto que acción institucional de la Iglesia y eclesiásticamente mediada, la que, por cierto, no agota las posibilidades de la libre acción de Dios por su Espíritu más allá de los límites de la Iglesia Católica, tal como lo reconoce la GS 22. Es lo que intento mostrar en lo que sigue.

20 CELAM, Documento conclusivo V Conferencia..., 14.

21 BERNHARD WeLTE, ¿Qué es creer? Ideas para una filosofía de la religión (Barcelona: Herder, 1984), 13.

22 Cfr. PAPA Pablo VI, «Evangelii Nuntiandi - Acerca de la Evangelización en el mundo contemporáneo», 1975, 63. 
evangelización. Ello supone reconocer que la acción salvífica de Dios no pasa únicamente a través de las mediaciones institucionales de la Iglesia, sino que obra a través de diversos medios solo por Dios conocidos. Y que, por ello, en el encuentro con el otro en la acción misionera siempre es posible encontrarse con el Espíritu ya actuante de Dios que nos antecede, que obra misteriosamente y que prepara el camino a la evangelización explícita a la cual la Iglesia está llamada.

\section{Desafíos Para la EVANGElización y PARA la teOlogía}

Ahora bien, a la luz de lo dicho hasta aquí, es posible y válido preguntarse cuáles son los desafíos que se desprenden de una tal comprensión de la evangelización y del lugar que ocupa el interlocutor en ella, tanto para la acción pastoral de la Iglesia como para la teología en su labor de inteligencia de la fe. Concluyo la presente conferencia presentando tres que me parecen especialmente relevantes.

La primera conclusión que surge, de manera bastante evidente, dice relación con la necesidad que tiene la Iglesia de redefinir la manera en la que se comprende -explícita e implícitamente- la evangelización, reconociendo el lugar central que ocupa el otro en ella como un verdadero interlocutor en el proceso de compartir la experiencia de Dios. La acción evangelizadora ya no puede seguir siendo comprendida como transmisión de la fe si por ello se entiende la entrega unilateral de un mensaje o una experiencia a un receptor supuestamente vacío o carente de ellos.

Ahora bien, para que ello sea así y la evangelización se transforme en una verdadera acción comunicativa ${ }^{23}$ se requiere que ambos interlocutores (Iglesia y mundo) se reconozcan como tal y compartan -ambos- la experiencia que en forma más o menos explícita han hecho de Dios. Implica que la actitud misionera no sea solo de anuncio (aunque igualmente lo es) sino también de escucha, de atención, de profundo discernimiento, para poder auscultar la acción del Espíritu en aquel con quien me encuentro. Incluso en aquellos que pueden haber tomado profunda distancia con la mediación eclesial. Pues ello no significa, inmediatamente, que hayan dejado de hacer experiencia de Dios en sus vidas, que no lo sigan buscando o que Dios esté definitivamente ausente.

23 Cfr. Jürgen Habermas, Teoría de la acción comunicativa (Madrid: Taurus, 1987). 
De ser así, la acción misionera puede y debe implicar también para la Iglesia la posibilidad de reconocer a Dios actuante más allá de los límites de sí misma y de profundizar en su propia fe y seguimiento al abrirse a la experiencia que otros están haciendo de Dios en sus vidas, a su modo, a través de diversas mediaciones. De esta manera, la misión puede ser una importante oportunidad para que la Iglesia se enriquezca y vuelva a abrir sus sentidos a ese Dios misterioso que de maneras desconocidas sigue actuando en el mundo y no se deja atrapar o reducir por categorías, mediaciones o formas ya reconocidas.

Por tanto, la tarea evangelizadora de la Iglesia como comunicación de la fe es doble: comunicar la fe que a su vez ha recibido y, al mismo tiempo, reconocer la presencia salvífica de Dios que de algún modo ya está actuando en aquellos con quienes la misión pone en contacto. Ello implica el desafío no solo de anunciar o transmitir la fe sino también de escrutar o auscultar lo que Dios dice en el mundo de hoy como parte constitutiva de la acción evangelizadora ${ }^{24}$. Solo así se podrá superar la tentación de comprender la evangelización como una entrega unidireccional de un mensaje (por parte de la Iglesia) que debe ser recibido por un receptor cuya experiencia es más o menos irrelevante para el proceso evangelizador y para la fe de la propia Iglesia.

Ahora bien, de lo anterior se desprende un segundo desafío de carácter teológico pastoral. Este dice relación con la necesidad que tiene la Iglesia de poder conocer a sus interlocutores y su sustrato religioso para el logro de una verdadera comunicación de la fe, es decir, para el anuncio de la buena noticia del encuentro personal y comunitario con Jesucristo así como para el discernimiento de la acción de Dios en la historia actual. Ello supone entonces la necesidad de conocer profundamente el tiempo presente e identificar cómo en él, Dios y hombre se van encontrando; ya no solo para poder identificar las disposiciones previas de los interlocutores de cara a la evangelización, sino también para poder auscultar en la historia actual la presencia actuante de Dios hoy.

24 Cfr. Concilio Vaticano II, Constitución Pastoral..., 4; Concilio Vaticano II, Ad gentes: decreto sobre la actividad misionera de la Iglesia (Madrid: Propaganda Popular Católica, 1965), 11; PAPA JUAN PABLO II, Redemptoris missio: carta encíclica sobre la permanente validez del mandato misionero, 2014, 56. 
Ahora bien, dada la pluralidad y desinstitucionalización religiosa comentada al inicio de esta conferencia, dicho discernimiento supone la necesidad de que la teología amplíe las categorías a partir de las cuales ella comprende la religiosidad, permitiendo integrar aquellas que vayan más allá de las tradicionalmente orientadas a la Iglesia ${ }^{25}$. El nuevo contexto religioso invita a preguntarse, de una manera más genérica, acerca de las experiencias y disposiciones que los interlocutores -todos sus interlocutores- han hecho o están haciendo ya no en relación a la Iglesia, sino en relación a Dios o incluso, en términos más generales, a lo divino. Es decir, intentar comprender un poco más ampliamente cómo se configura hoy en Chile la experiencia religiosa ${ }^{26}$, entendida como un tipo de experiencia humana que conecta o comunica al hombre con una realidad superior (la realidad divina, sobrenatural, lo trascendente o Dios) y que define la forma en que el ser humano entiende el mundo y su propia vida $^{27}$. Este concepto -ampliamente utilizado en literatura religiosa o en estudios referidos al fenómeno religioso- tiene la ventaja de que permite integrar una vasta gama de posibles expresiones de la relación del sujeto con lo divino, más allá de las tradicionalmente reconocidas como tal.

Una ampliación conceptual de este tipo en la manera de acercarse pastoralmente a los interlocutores de la misión supone hacerse preguntas como: ¿Buscan y anhelan las personas hoy un encuentro personal con Dios? ¿Cómo comprenden, viven y expresan el hombre y la mujer de

25 Cfr. Thomas Luckmann, La religión invisible: : el problema de la religión en la sociedad moderna (Salamanca: Sígueme, 1973).

26 Cfr. Charles Glock y Rodney Stark, Religion and society in tension (Chicago: Rand McNally, 1965); Alberto Dou y Juan Martín Velasco, eds., Experiencia religiosa, Estudios interdisciplinares; 15 (Madrid: UPCM, 1989); RAYMOND PANIKKaR, La experiencia de Dios (Madrid: PPC, 1994).

27 Cfr Karel Dobbelaere, Secularization: An Analysis at Three Levels (Peter Lang, 2002).; Rudolf Otтo, Lo santo, lo racional y lo irracional en la idea de Dios, 2a ed. (Madrid: Revista de Occidente, 1965).; Rodney STARK, «A Taxonomy of Religious Experience», Journal for the Scientific Study of Religion 5, $\mathrm{n}^{\circ} .1$ (octubre de 1965): 97-116.; Max Scheler, De lo eterno en el hombre (Madrid: Encuentro, 2007).; Friedrich Schleiermacher, Sobre la religión : discursos a sus menospreciadores cultivados, Colección clásicos del pensamiento ; 76 (Madrid: Tecnos, 1990).; Bernhard Welte, Filosofía de la Religión, Biblioteca Herder. Sección de Teología y Filosofía 166 (Barcelona: Herder, 1981). 
hoy su relación con lo sagrado ${ }^{28}$ ? ¿Cuáles son las creencias, prácticas y experiencias que ellos catalogan como religiosas pues de alguna manera los conectan con dicha realidad ${ }^{29}$ ? ¿Qué implicancias tiene para su vida la relación con lo divino? Entre otras. Sólo así la Iglesia podrá realizar una reflexión teológico-pastoral actualizada y pertinente en torno a la evangelización en el mundo de hoy, que le permita realizar propuestas pastorales fructíferas que tomen en serio a sus interlocutores y puedan vincular el anuncio cristiano a las búsquedas y experiencias religiosas ya presentes en ellos. Pero más aún, solo así la teología podrá intentar discernir cómo Dios sigue actuando en la historia y cómo el encuentro entre Dios y el hombre sigue hoy aconteciendo más allá de los límites tradicionales.

Ahora bien, la necesidad de comprender más ampliamente la experiencia religiosa actual levanta nuevas preguntas y un tercer desafío a la teología pastoral: ¿Cómo puede la teología, desde su propia perspectiva, conocer y comprender mejor la experiencia religiosa del hombre de hoy? ¿Cuáles son las herramientas que tiene esta disciplina a su disposición para un desafío de esta envergadura? ¿Cuál es el rol que juegan, a este respecto, las teorías y las mediaciones empíricas para una mejor comprensión del fenómeno religioso actual? ¿Cómo puede la teología hablar responsablemente del mundo de hoy y de la presencia y acción de Dios en él? ¿Cómo puede ella incorporar, dentro de su labor de inteligencia de la fe, la experiencia religiosa del hombre contemporáneo?

El hecho de que las preguntas planteadas comiencen con el pronombre interrogativo ¿cómo? implica que esta necesidad no es sólo una cuestión de declaración de intenciones, sino puntualmente una cuestión metodológica: la necesidad que tiene la teología de contar con un método que le permita incorporar, como un momento inherente a su labor, la experiencia religiosa actual. Ello, como explicitan algunos autores, no es una cuestión meramente instrumental, secundaria o externa:

28 Cfr. Danièle Hervieu-Léger, Religion as a Chain of Memory (New Brunswick, N.J: Rutgers University Press, 2000).

29 Cfr. Ann TAves, Religious Experience Reconsidered: A Building-Block Approach to the Study of Religion and Other Special Things (Princeton, NJ: Princeton University Press, 2011). 
La cuestión acerca del método del pensar creyente define la manera concreta como la Iglesia enfoca en los más diversos problemas humanos: o bien desde una postura más deductiva, que aplica principios inmutables a realidades cambiantes o, por el contrario, desde una orientación más inductiva, que destaca el valor de lo particular, de lo histórico-concreto, a la luz de lo cual, incluso los principios, encuentran una nueva iluminación y comprensión. [...]. En ella está en juego, más bien, la posibilidad de que la Iglesia, la fe y la teología sean un poco menos impermeables a las inquietudes que emergen de las complejas experiencias biográficas ${ }^{30}$.

Se plantea así la necesidad de un método teológico que incorpore, como objeto específico de estudio, la acción de Dios en la historia en su carácter contemporáneo; ello en vistas a poder identificar las experiencias religiosas ya presentes en los interlocutores de la evangelización, de modo de hacer de ella una acción más fructífera. Pero también para comprender y reconocer a la historia como verdadero lugar teológico y, por tanto, como fuente de reflexión y generación de conocimiento al interior de esta disciplina. En este segundo sentido, el desafío desborda los límites de la Teología Pastoral, y se transforma en una tarea fundamental a toda teología.

Para responder a este desafío, dicho método debe orientarse a reflexionar teológicamente la experiencia actual como parte del proceso de generación de conocimiento, y no sólo como un paso previo o preteológico. La dimensión inductiva debe incorporarse de manera aún más radical, para que sea verdaderamente una mediación teológica. "El presente no puede ser considerado como mera situación a la cual se aplican las verdades evangélicas, sino que debe reconocérsele su carta de ciudadanía en el seno del círculo teológico; es preciso, pues, esforzarse en una interpretación teológica del mismo"31. Evidentemente, una propuesta

30 Carlos Schickendantz, «Una elipse con dos focos. Hacia un nuevo método teológico a partir de Gaudium et Spes», en Teología de los signos de los tiempos latinoamericanos : horizontes, criterios y métodos (Santiago, Chile: Ediciones Universidad Alberto Hurtado, 2013), 57.

31 Juan Noemi, «En la búsqueda de una teología de los "signos de los tiempos"», en Signos de estos tiempos. Interpretación teológica de nuestra época (Santiago, Chile: Ediciones Universidad Alberto Hurtado, 2008), 84. 
metodológica de este tipo requiere ser -por las características del objeto de estudio: la experiencia religiosa en su expresión actual-interdisciplinar y empírica ${ }^{32}$.

A este respecto, me ha parecido especialmente sugerente la propuesta de la denominada "Teología Empírica" 33, propuesta metódica surgida hace ya más de 50 años en Holanda y que busca poder estudiar, desde una perspectiva teológica pero constitutivamente intradisciplinar, la experiencia religiosa presente como una fuente de desarrollo teológico en diálogo hermenéutico con otras fuentes tradicionales como son las Sagradas Escrituras y la Tradición. Para ello, la Teología Empírica propone que sean los mismos teólogos prácticos quienes incorporen, dentro de sus competencias investigativas, las herramientas e instrumental empírico de las ciencias sociales, para el estudio de la experiencia religiosa en su expresión actual. Ello permite que la teología se haga parte de los procesos de generación de los marcos de referencia epistemológicos y conceptuales a partir de los cuales se realiza la investigación, así como en la definición de los modelos conceptuales y operacionales y los instrumentos más adecuados para el estudio empírico del objeto de estudio. Solo así, la teología puede evitar la mera yuxtaposición disciplinar que supone, por ejemplo, la interpretación teológica posterior de datos sociológicos levantados con anterioridad desde otros marcos conceptuales. Dicho método logra incorporar, desde mi parecer, los principales avances que la teología contemporánea ha logrado realizar en torno a la comprensión de la revelación y el valor teológico de la historia y que han sido sistematizados en el apartado anterior; pero da un paso más, desarrollando una reflexión propiamente metodológica necesario e indispensable para abordar el desafío de reflexionar teológicamente la historia actual.

En síntesis y para concluir, me parece que hoy ni la evangelización ni la teología como fe que busca su propia inteligencia pueden desarrollarse sin tomar en cuenta las actuales expresiones de la fe de nuestros pueblos, incluso en momentos como los actuales en los cuales ella avanza hacia una mayor pluralización. Ambas requieren integrar, como un momento

32 Cfr. Joaquín Silva, «Theory and Empirical Research in Liberation Theology», en ET-Studies 7, n 1 (2016): 160.

33 Cfr. Johannes van der Ven, Practical Theology: An Empirical Approach (Leuven: Peeters, 1998). 
dentro de su propio desarrollo, el conocimiento acerca de cómo el hombre de hoy comprende y vive su referencia a o relación con la trascendencia. Ya sea como un medio para la identificación de pistas para una mejor comunicación de la fe así como para realizar un ejercicio de verdadero discernimiento de la acción amorosa de Dios en la historia; también en la de hoy. 